\title{
A Novel Design of Hybrid Hydrophilic-Superhydrophobic Surfaces for Fog Harvesting
}

\section{Zaid Almusaied and Bahram Asiabanpour}

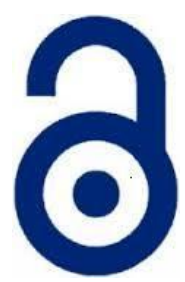

\author{
Received: 28 February 2021 \\ Accepted: 01 May 2021 \\ Published: 15 July 2021 \\ Publisher: Deer Hill Publications \\ (c) 2021 The Author(s) \\ Creative Commons: CC BY 4.0
}

\begin{abstract}
The continuous growth in the human population and climate change exacerbates the problems related to water scarcity. Harvesting the atmospheric water can mitigate the water scarcity in many regions around the globe. Fog collection using hybrid hydrophilic-superhydrophobic surfaces has the capacity to achieve a higher water collection rate. In this paper, a new method and materials are introduced to create the hybrid surfaces. The method includes additive manufacturing- to make sheets with holes-, mixing and casting polymeric matrix composite, and a controlled spray coating mechanism. The materials comprised of hydrophobic coating on top of the acrylic printed sheet and hydrophilic composite. The ratios of the pitches to diameters of the hydrophilic regions varied during the experiments to obtain the best water generation. The water collection rate for the sample with diameters of 583 um and a pitch of 1600 um has achieved $57 \%$ more than the untreated hydrophilic sample. The contrast in wettability accomplished by this novel method has the potential to be implemented on a large scale for atmospheric water harvesting.

Keywords: Hydrophilic, Superhydrophobic, Hybrid Surfaces, Fog Harvesting, Additive Manufacturing
\end{abstract}

\section{INTRODUCTION}

Water is considered one of the most fundamental substances to life on Earth. It comprises a significant percentage of all living creatures; $60 \%$ of an adult human body is made of water [1]. The projection of the World Health Organization (WHO) for drinking and domestic needs of water is averaging from 50 to 100 litres per person per day [2]. Furthermore, water is needed and used heavily in agriculture and various industries. The Food and Agriculture Organization (FAO) forecasted that 1.2 billion people already reside in agricultural regions facing insufficient water supply [3-4]. Urban areas around the globe are likewise facing shortages with quantity and/or quality. The United Nations' projection for the urban dwellers not having adequate supply and management of water increased by $50 \%$ since 2000 [5]. The continuous growth in the global population will increase the demand for freshwater, and more areas will face the shortage. The water crises are also aggravated by climate change through the increase in droughts occurrence [6]. The United Nations expects 4.8 to 5.7 billion people to suffer from water shortage by 2050 for at least one month per year [7].

While water covers $71 \%$ of our planet, less than $1 \%$ of this water is usable freshwater [8]. Many approaches have been considered and pursued to overcome water shortages. Seawater desalination is one of them, yet the process requires high investment and consumes high energy [9]. One of the other approaches to solve the water crisis is to collect water from sustainable-untapped resources such as the water in the atmosphere. The estimation of the amount of water in the atmosphere is about 3000 cubic miles [8]. The water in the atmosphere can be in a gaseous or condensed form. The fog consists of tiny water droplets that reside in the air, with a small diameter ranging from 1 to 40 um [10].

Many floras and faunas have evolved throughout millions of years to survive in a harsh dry environment by harvesting the atmosphere's water. Among the many observed creatures to do so are the Namib beetle desert (Stenocara gracilipes), various Cactaceae species, the green tree frogs (Litoria Caerulea), the cribellate spider (Uloborus walckenaerus), and the Bermuda grass (Cynodon dactylon) [11-13]. These creatures have unique wetting characteristics and surface structures that lead to efficient water generation either by dewing or fog basking. The dewing process includes a phase transfer where the water vapor condenses into the water as the temperature drops below the dewpoint. In comparison, fog basking is mainly a collection of fog's tiny water droplets.

Almusaied, Z. I. and Asiabanpour, B. $\square$

Ingram School of Engineering- Texas State University

San Marcos, TX 78666 USA

E-mail: ba13@txstate.edu

Reference: Almusaied and Asiabanpour (2021). A Novel Design of Hybrid Hydrophilic-Superhydrophobic Surfaces for Fog Harvesting. International Journal of Engineering Materials and Manufacture, 6(3), 152-162. 
The Stenocara beetle inhabits the Namib desert, where the annual rainfall is fewer than $13 \mathrm{~mm}$, and the fog happens around 30 days per year [9]. The beetle's dependence on fog harvesting was a source of intensive studies and biomimicry. The pioneering work of Parker and Lawrence (2001) suggested that the beetle's dorsal consists of random hydrophilic bumps, with a diameter of $0.5 \mathrm{~mm}$ and a pitch of $1-1.5 \mathrm{~mm}$ in the middle of the waxy hydrophobic region [14]. More recent studies by Nørgaard and Dacke (2010) postulate that the Stenocara beetle has a hydrophobic surface rather than a hybrid hydrophilic-hydrophobic nature [15]. Yet, the research to make and study hybrid surfaces for both condensation and fog harvesting during the last couple of decades has successfully shown such surfaces' efficiency [16-24]. The construction of hybrid surfaces by the researchers varied with materials, processes, and their complexity.

Parker and Lawrence (2001) created a simple hybrid surface by embedding hydrophilic sphere glasses with a diameter of $0.6 \mathrm{~mm}$ in hydrophobic wax [14]. The water collection rate of their hybrid surface was more than that of the hydrophobic wax [14]. Mondal et al. used needles as the hydrophilic part and penetrated them through superhydrophobic sheets to create hybrid surfaces for water collection by dewing [16]. Hou et al. formed the hybrid surface using photolithography and etching to fabricate hydrophilic micro-pillars of silicon dioxide surrounded by superhydrophobic fluorinated Nano-grass and tested their condensation efficiency [17]. Garrod et al. created the hybrid surfaces by plasmachemical deposition and modification with a broad study of the affective dimensions, and pitches of the hydrophilic part to the hydrophobic region were implemented [18]. Zhang et al. (2015) used inkjet printing to achieve a micropattern of the hydrophilic array on top of the superhydrophobic layer [19]. Their printed super hydrophilic array was created by in situ polymerization of polydopamine [19]. Wang et al. (2015) made the biphilic surface by using thermal pressing to attach treated superhydrophobic metal gauzes to a hydrophilic polystyrene sheet [22]. Wong et al. (2015) created a hybrid surface of micropatterned hydrophilic poly (2hydroxypropyl methacrylate) on hydrophobic polystyrene with the dewetting process [24].

While the aforementioned methods successfully created and examined the efficacy of the hybrid surfaces with different sizes, the majority of them used expensive and complicated procedures. In this paper, a new, inexpensive method is introduced to create hybrid surfaces. The hybrid surfaces made here consist of an array of hydrophilic regions in the middle of a superhydrophobic. The surfaces are fabricated using additive manufacturing, spray coating, polymeric matrix composite mixing, and casting. The paper postulates that the water collection rate (WCR) can be enhanced by using the new hybrid surfaces. Furthermore, the research explores the hybrid surfaces' WCR by changing the hydrophilic region's diameter and between them. The rest of this paper is organized as the following. In section 2 , materials, equipment, samples' preparation, and experiment setup are presented. Section 3 illustrates the results and discussion including the samples' dimensions, samples' wettability, and the water collection rate for the samples. The conclusion is presented in Section 4.

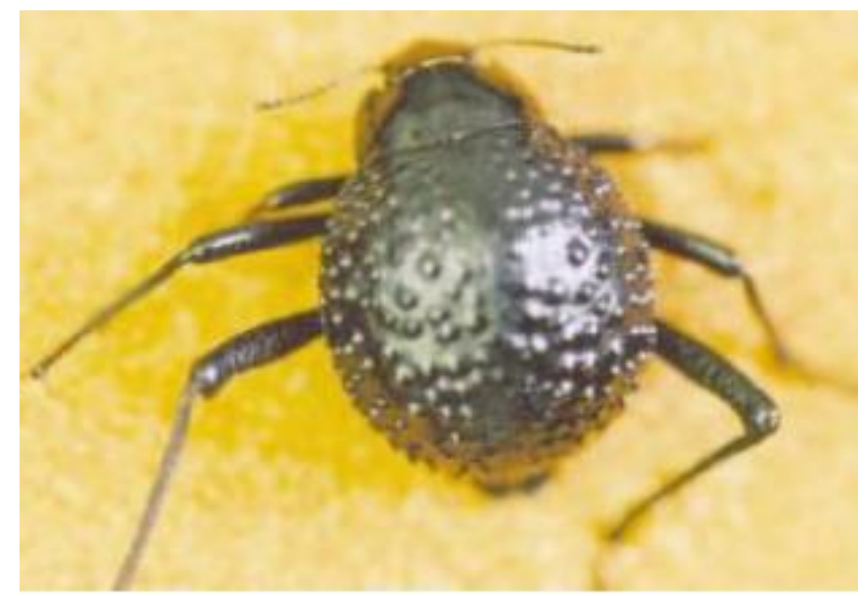

Figure 1: The Stenocara gracilipes. The beetle inspired the research of hybrid surfaces. The beetle inhabits the Namib desert, and it depends on fog to generate its water [14].

\section{MATERIALS, EQUIPMENT, SAMPLES PREPARATION AND EXPERIMENT SETUP} 2.1 Design, Materials, Equipment, and Samples Preparation

In this research, eight samples were prepared. The samples were distributed as follows: six were hybrid surfaces, one hydrophilic, and one superhydrophobic. The sample's preparation included the design of the sample and separate implementation of the superhydrophobic portion and the hydrophilic part, and finally attaching them to create a controlled array of hydrophilic regions in the superhydrophobic area. 


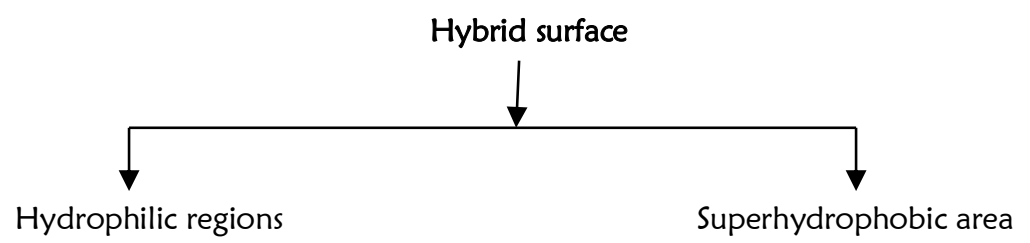

The design criteria for the hybrid surfaces include a four-by-four array of hydrophilic circles. The diameter of the circles is designed to be 400 um for three samples and 500um for the other three. The pitches for the hydrophilic regions are designed to vary from $1.5,2$, and 3 of the diameters.

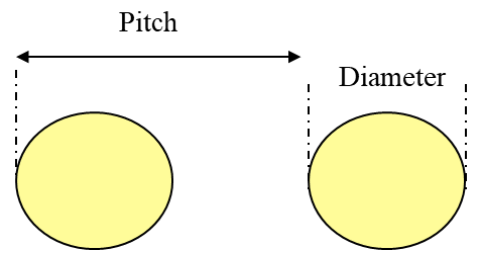

Figure 2: The holes' diameters and pitches of the sheets. The purpose of the design is to control the ratio of the superhydrophobic to the hydrophilic area in the samples.

Table 1: The design criteria for two different diameters with three pitches for the hybrid surface to evaluate the best ratio to enhance the water collection rate.

\begin{tabular}{cccc}
\hline Hole diameter & Pitch $=1.5$ Diameter & Pitch $=2$ Diameter & Pitch $=3$ Diameter \\
\hline 400 & 600 & 800 & 1200 \\
500 & 750 & 1000 & 1500 \\
\hline
\end{tabular}

The superhydrophobic part is made using additive manufacturing and spray coating. The designs were first created using AutoCAD Inventor. The samples' peripheral dimensions were $14.5 \mathrm{~mm}$ by $12.5 \mathrm{~m}$, while the thickness of the sheets designed to be 100um. Additionally, two L-shape frames were added to each sample to prevent the warping of the sheet due to the cleaning and its small thickness.

Polyjet 3D printer (Stratasys objet260) is used to print the samples. The materials used for printing are made of acrylic monomer, exo-1,7,7-trimethylbicyclo (2.2.1) hept-2-yl acrylate; tricyclodecane dimethanol diacrylate, photoinitiator, acrylic oligomer, and titanium dioxide. The printing ensured minimum support material by including the optimum orientation, glossy and high-quality print settings. The printed sheets were collected and cleaned manually using a spatula and DI water, then sonicated with non-ionic soap and DI water for ten minutes for each step. Later, the sheets were cleaned with acetone, methanol, isopropanol. The next step was converting the printed sheets into superhydrophobic by coating them. The superhydrophobic coating was made by mixing $10 \mathrm{mg} / \mathrm{ml}$ of hydrophobic fumed silica and ethanol. The sheets attached to a slide glass and airbrush were used to coat them. A controlled speed stage was made to ensure consistency for all samples. The stage consisted of a lead screw, Arduino, stepper motor, and dual $\mathrm{H}$ bridge driver. The airbrush used a pressure of $3.8 \mathrm{bar}$, and it was held vertically $22 \mathrm{~cm}$ from the stage. The stage speed was $40 \mathrm{rpm}$ with a correspondent linear speed of $320 \mathrm{~mm} / \mathrm{min}$.

The hydrophilic part was made using polymer matrix composite with copper powder as filler. The used copper powder Particle size was 325 mesh $(0.1 \%>63 \mu \mathrm{m}, 96.1 \%<45 \mu \mathrm{m})$ [25]. The resin of the matrix material is made of Bisphenol A-epichlorohydrin polymer $(=>60 \% \mathrm{w} / \mathrm{w})$, and $(3(2,3$ Epoxypropoxy) propyl) trimethoxy silane $(>=$ 0.1) [26]. The hardener is made of: Isophorone diamine $(7-13 \% w / w)$, Bisphenol A $(0.1-1 \% w / w)$, Diethylenetriamine $(0.1-1 \% \mathrm{w} / \mathrm{w})$, and Tetraethylenepentamine $(0.1-1 \% \mathrm{w} / \mathrm{w})$ [27]. An equivalent volume of resin and hardener were used to create the composite polymeric matrix. The overall composite mixture was created with a weight percentage of $25 \%$ of the polymer and $75 \%$ filler. The composite consisted of $0.125 \mathrm{~g}$ of resin, $0.125 \mathrm{~g}$ of hardener, and $0.75 \mathrm{~g}$ copper powder. The composite component mixed for three minutes and leveled for another one minute. The composite was mixed inside a prepared silicon-based mold. The mold dimensions were 15, 25.4, and $1 \mathrm{~mm}$. The manual mixing was performed with a spatula for three min and the leveling for another minute.

The final step for the sample preparation was attaching the coated sheets to the prepared composite; this was done after six minutes from the start of the mixing. Later, the samples were detached from the molds after 24 hours. 
Furthermore, the two additional samples with no hole in the design were prepared, one was coated to become only superhydrophobic, and the other was without coating (to be only hydrophilic).

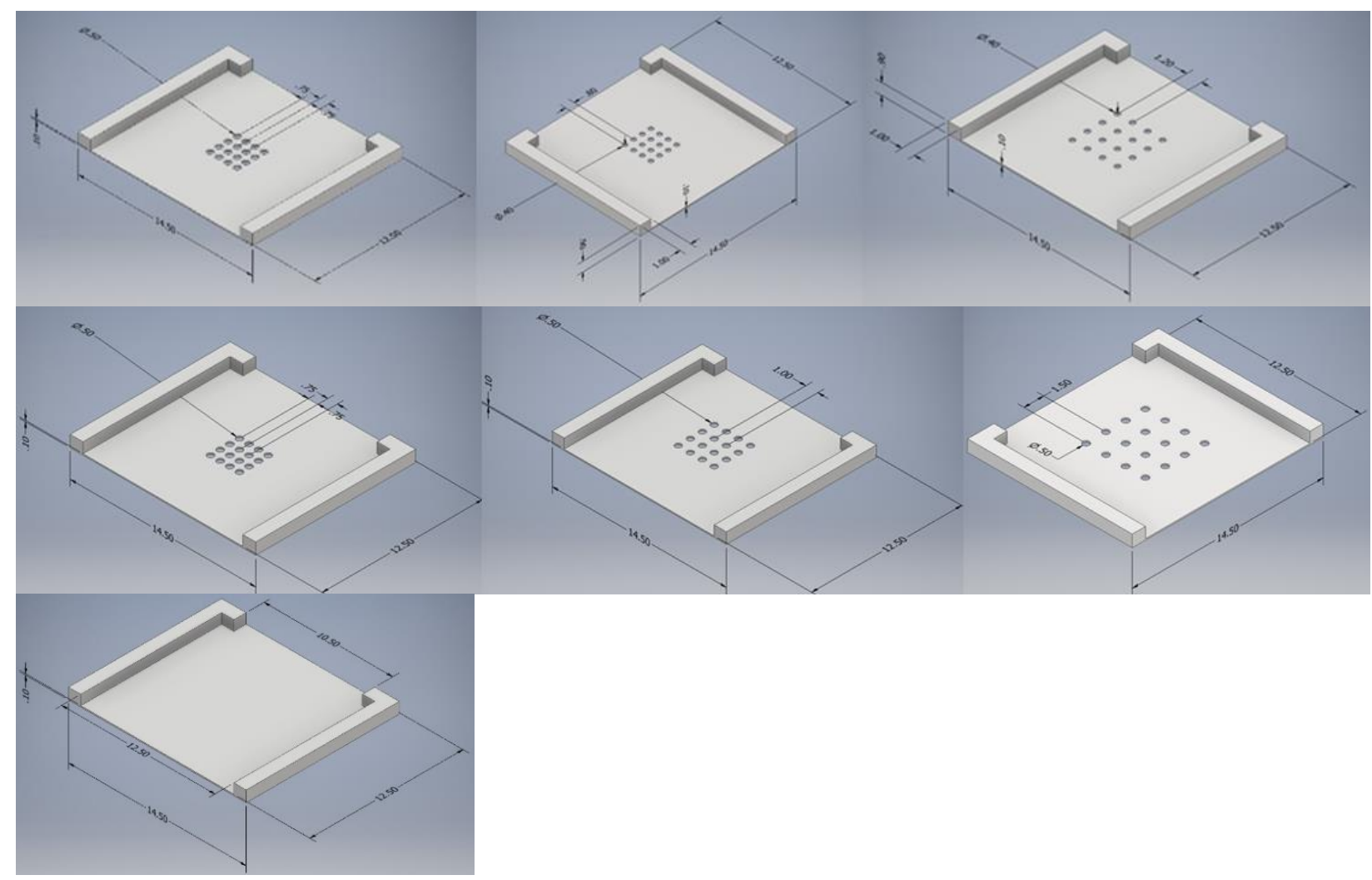

Figure 3: The seven CAD designs to implement the six hybrid surfaces, hydrophilic, and superhydrophobic samples for the experiments.
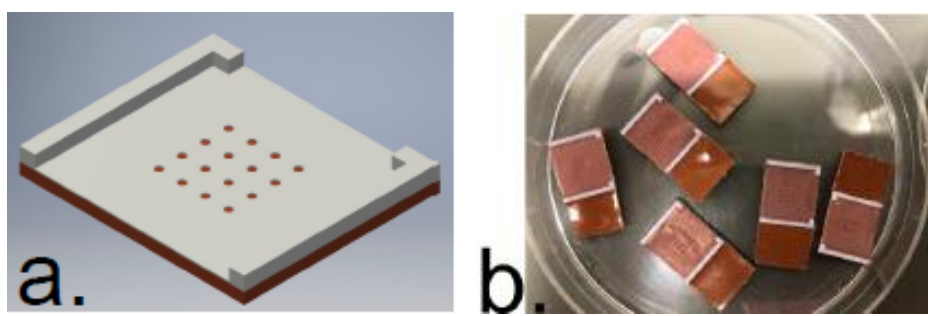

Figure 4: a. The design of the sample as it's attached to the composite. b. The prepared samples with different diameters and pitches

\subsection{The Experiment's Setup}

The WCR of the samples was tested in a lab environment with $\mathrm{fog} / \mathrm{mist}$ emulation. A commercial humidifier (Levoit model $\mathrm{LV} 600 \mathrm{HH}$ ) was used for this purpose. The flow velocity was measured as $0.5 \pm 1 \mathrm{~m} / \mathrm{s}$.

The mist was generated with an average of $300 \mathrm{ml} / \mathrm{h}$ and ejected with an angle of $50^{\circ}$. A sample holder was designed and printed. The sample's distance from the humidifier outlet was $12.5 \mathrm{~cm}$. The average humidity of the sample was measured to be around $90-95 \%$, and the experiments were done at a room temperature of $21 \pm 1{ }^{\circ} \mathrm{C}$. 
a.

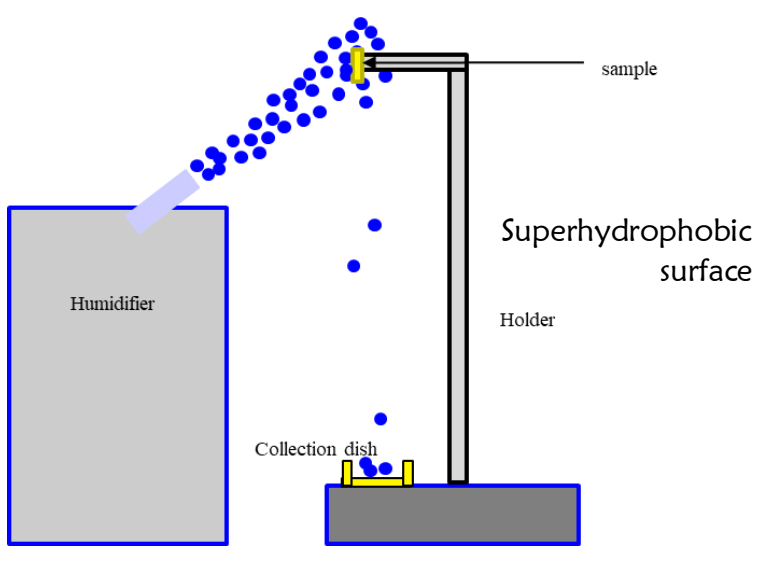

Figure 5: a. The schematic of the experiment's settings. b. water collection on the sample

\section{RESULTS AND DISCUSSION}

Three types of results obtained for the experiments:

- Samples' dimensions

- Samples' wettability

- The water collection rate for the samples

\subsection{Samples' Dimensions}

The dimensions of hybrid surfaces' components were determined using both stereomicroscope and digital microscopy (Hirox Digital Microscope). The diameters of the holes and their pitches were measured for the sheets after printing. While the estimated pitches were close to the design, the diameters were less by different percentages. The designs were modified by adding 200 um for each diameter. The new calibrated samples were printed again and measured. Furthermore, the calibrated samples were used to fabricate the hybrid surfaces and were finally measured.

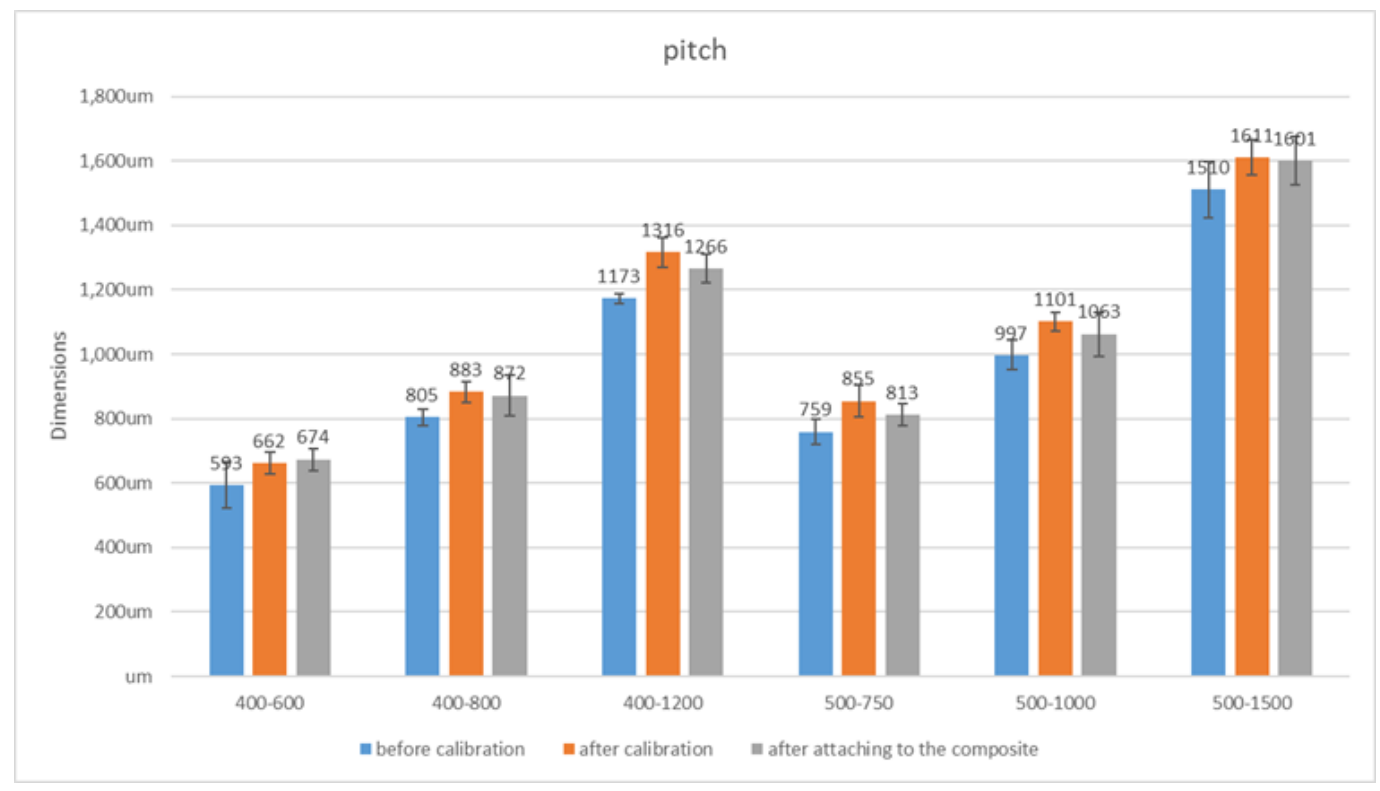

Figure 6: The samples' pitches were measured using a stereomicroscope. The original designs were later modified by adding 200 um for the diameters. This was done due to the limitations of the printer and to make the diameter close to the intended designs. 


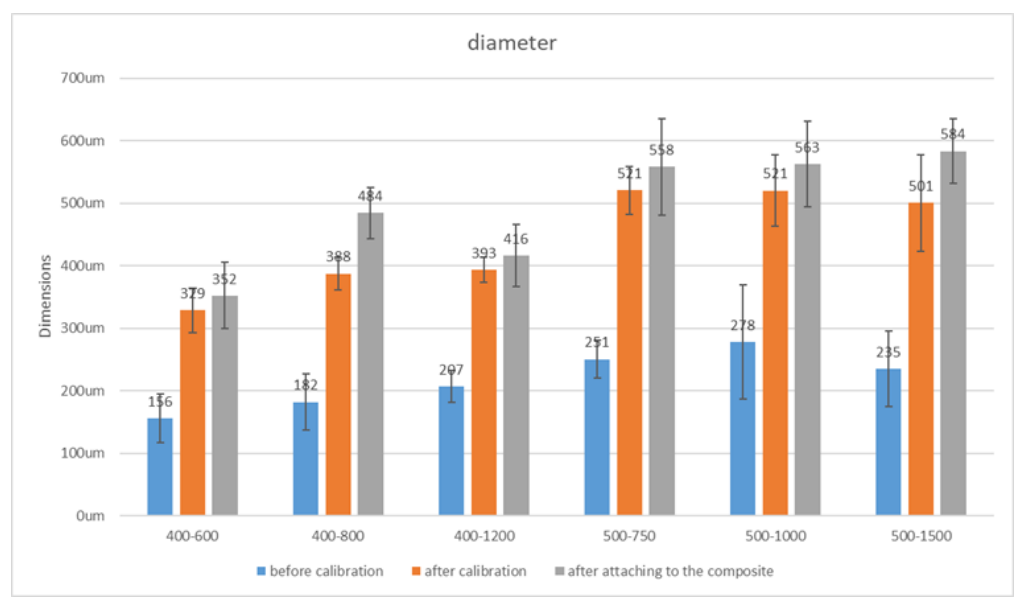

Figure 7: The samples' diameters were measured using a stereomicroscope. The original designs were later modified by adding $200 \mathrm{um}$ for the diameters. This was done due to the limitations of the printer and to make the diameter close to the intended designs.

The overall observation for the dimensions of the printed sheet is higher accuracy of the pitches compared to the diameters of the holes.

The thickness of the printed sheets, composite, and coating layers were measured using the digital microscope. A sliding glass was partially covered with scotch tape and coated with the exact coating mechanism, later the tape was removed, and a step was created for the measurement. The total thickness for the sample designed with diameters of 500 um and a pitch of $1500 u m$ was $787 \pm 20$ um.

Table 2: The layers thicknesses for the sample designed with diameters of 500um and a pitch of 1500um as measured optically

\begin{tabular}{ccc}
\hline Layer & Thickness & Uncertainty \\
\hline Composite thickness (Fig. 8) & $654 \mu \mathrm{m}$ & $\pm 11 \mu \mathrm{m}$ \\
Blank sheet (Fig. 9) & $113 \mu \mathrm{m}$ & $\pm 11 \mu \mathrm{m}$ \\
Four passes coating (Fig. 10) & $20 \mu \mathrm{m}$ & $\pm 13 \mu \mathrm{m}$
\end{tabular}

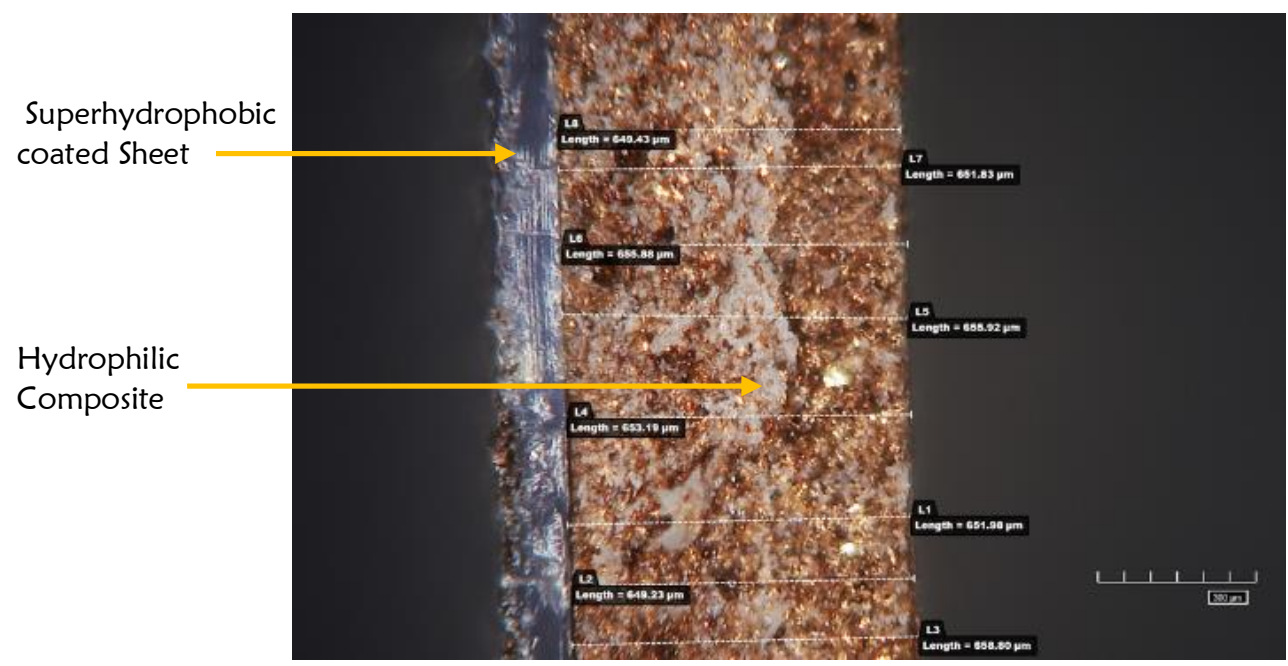

Figure 8: The coating was measured using the Hirox digital microscope. The coating on the glasses performed with the same conditions as on the sheet. 


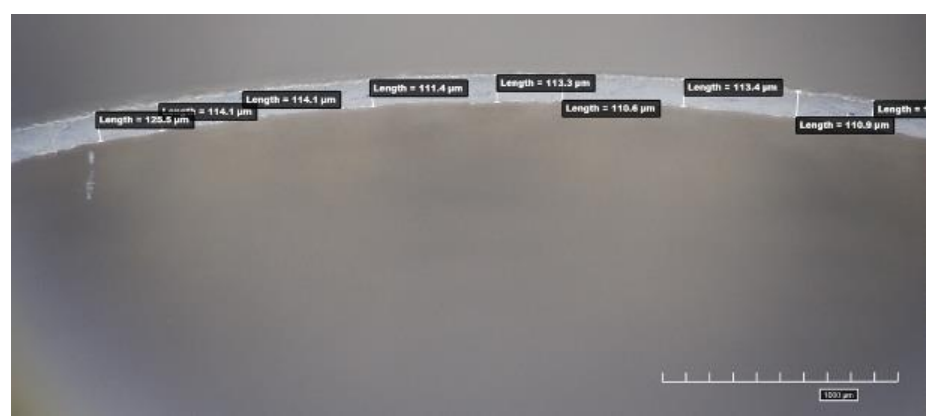

Figure 9: The uncoated sheet as measured by the Hirox digital microscope

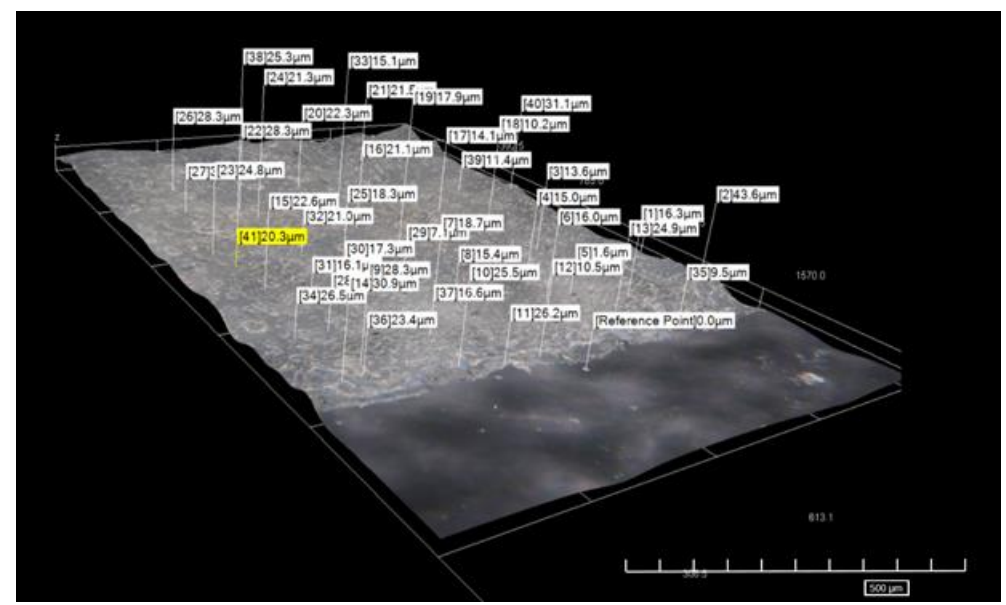

Figure 10: The composite thickness measured by digital microscope

\subsection{Samples' Wettability}

The wettability of the samples' component describes the behaviour of the contact between them and the water. The wettability is measured through the contact angle between the interfaces of the air-water and the solid-water at the three phases contact line. Multiple contact angles can occur with different local minimum free energy. These contact angles are encapsulated between the advancing and receding angles as they represent the maximum and minimum contact angles for the system [28]. The measurement of the advancing and receding contact angle was obtained using sessile-drop goniometry. DI water droplets were placed on the samples with the needle was halfway inside the droplets. Quasi-static conditions were created for the measurements by using an automated pump with a slow flow. The pump flow rate used in the experiment was $0.08 \mathrm{ul} / \mathrm{sec}$. The advancing contact angles were calculated as the water was pumped in until the baseline of the droplet started to move. At the same time, the receding angles measured with the water pumped out of the droplet, and the baseline began to shrink [29-30].

Table 3: The Advancing contact angle (ACA) and Receding contact angle (RCA) were measured using a goniometer. The droplet volume increased and decreased with $0.08 \mathrm{ul} / \mathrm{sec}$ to obtain quasi-static conditions

\begin{tabular}{cccc}
\hline Material & ACA & RCA & Hysteresis \\
\hline Hydrophilic sheet & $73.4 \pm 1.5$ & $50 \pm 2$ & $23.4 \pm 2.5$ \\
Hydrophilic composite & $72 \pm 0.4$ & $29.4 \pm 1.1$ & $42.6 \pm 1.2$ \\
$\begin{array}{c}\text { Superhydrophobic coated } \\
\text { sheet }\end{array}$ & $163.1 \pm 0.5$ & $161.7 \pm 0.6$ & $1.4 \pm 0.8$ \\
\hline
\end{tabular}



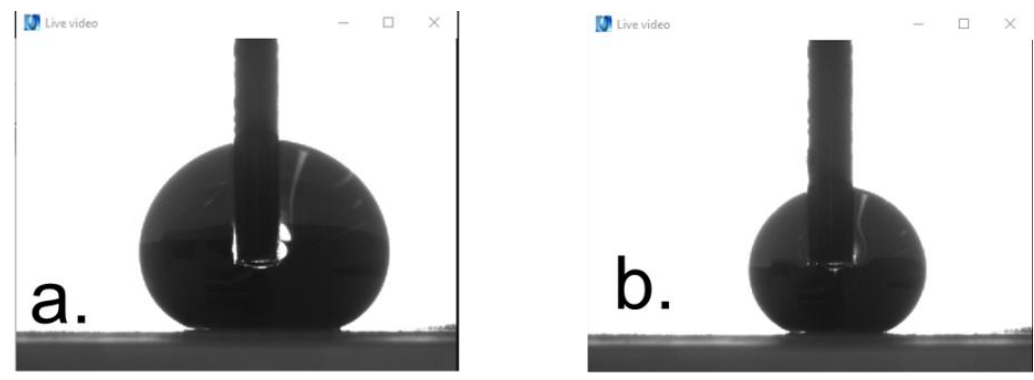

Figure 11: a. The ACA for the superhydrophobic area. b.The RCA for the superhydrophobic area. The measurements obtained using a goniometer and automated water dispenser with a volume rate of $0.08 \mathrm{ul} / \mathrm{sec}$

3.3 The Water Collection Rate for the Samples

The WCR of the eight samples was attained in the lab using a humidifier to emulate the fog.

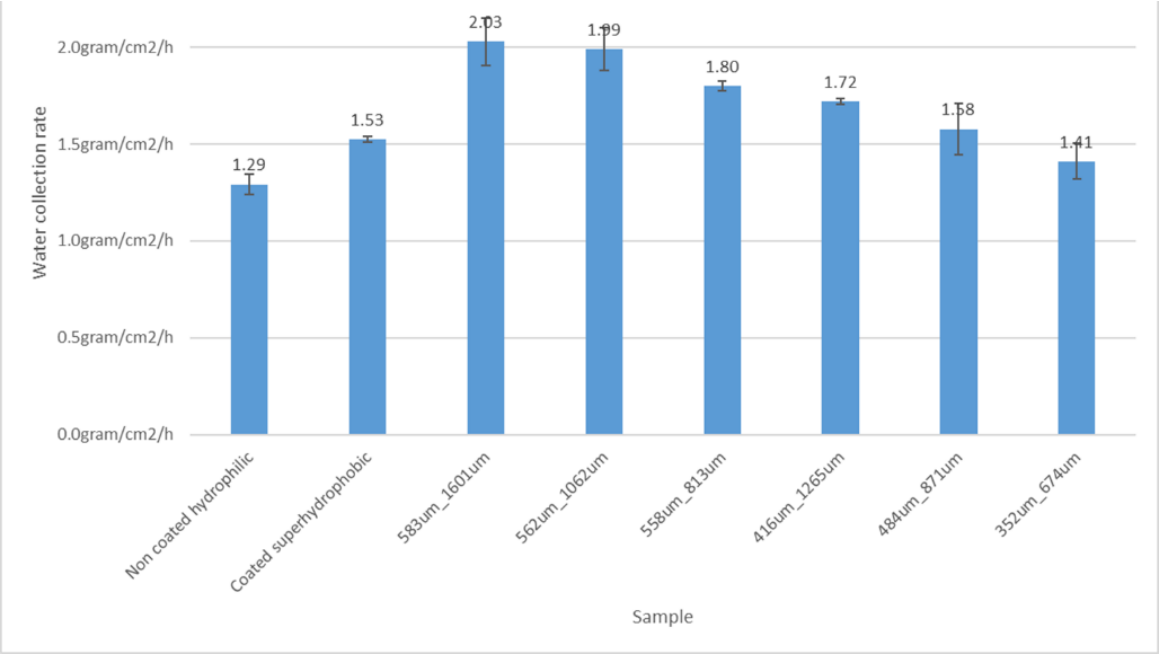

Figure 12: The water collection rate for the samples, including the homogeneous hydrophilic and homogeneous superhydrophobic samples

The WCRs for the six hybrid samples are more than that of the untreated hydrophilic sample. This can be explained through the analysis of the collection mechanism. The fog harvesting mechanism can be divided into three steps [3133].

- Collecting and capturing the deposited water droplets

- Migration and accumulation of the droplets

- The shedding

The first step of fog harvesting is majorly influenced by fog density. The second step started with the captured droplets on the surface beginning to move from the area with low surface free energy into the ones with high surface free energy. The driving force for the movement can be described by the following equation:

$\mathrm{F} 1=\gamma\left(\cos \theta_{1}-\cos \theta_{2}\right)-\cdots-\cdots(1)[34-35]$.

Where $\mathrm{F} 1$ is the droplet migration driving force, $\gamma$ is the water surface tension of the water, $\theta_{1}$ and $\theta_{2}$ are the contact angles of the hydrophilic and hydrophobic regions, respectively.

Thus, the higher contrast in wettability will create a more potent migration driving force and faster droplets growth on the hydrophilic regions. The droplets continue to grow on both the hydrophilic and the superhydrophobic regions; they still will be under a pinning capillary force that keeps them attached to the surfaces.

The third step: The shedding of the water droplets will start when the force exerted by gravity is more significant than the retention force. The previous condition is described by the Furmidge equation:

$m g \sin \alpha>\gamma l\left(\cos \theta_{r}-\cos \theta_{a}\right)$ 
Where $\mathrm{m}$ is the mass of the droplet, $\mathrm{g}$ is the gravity acceleration, $\alpha$ is the sliding angle, $\gamma$ is the water tension, $l$ is the width of contact of the droplet, $\theta_{r}$ is the receding angle on the hydrophilic region, and $\theta_{a}$ is the advancing angle for the hydrophobic region.

The measured low contact angle hysteresis for the superhydrophobic area indicates a Cassie-Baxter wetting condition. The Cassie-Baxter wetting condition is associated with minimum contact area between the droplets and the surface, as the air pockets exist underneath the droplets. Some of the droplets on the hybrid surfaces were observed not moving to the hydrophilic regions; this might indicate a wetting transition from the Cassie-Baxter regime into the more pinned Wenzel state. In the Wenzel state, the surface asperities penetrate the water droplet, and no air pocket exists. The transition happens primarily due to the young-Laplace pressure, making the droplet wet the air pockets underneath them. The aforementioned wetting's transition can also explain the water collection behaviour on the superhydrophobic sample.

The hydrophilic sample, on the other hand, showed less water collection as the water droplets created bigger pinned droplets which emulated the stagnate film is condensation.

In addition to the previous mechanism and affecting factor, additional variables influence the WCR, such as the wind speed, the distance from the source of mist, and the fog droplet size [32]. The droplet kinetic energy, due to the wind, helps the droplets' collection, migration, and shedding. On the other hand, a very small droplet size combined with high wind speed might lead to the loss of the droplets due to evaporation. Another factor that might influence the collection is the account of water vapor condensation into water. The previous mechanism assumed the WCR is only associated with fog water droplets, while the high saturation occurring during the experiment might lead to the water vapor phase transition.

\section{CONCLUSIONS}

- Hybrid surfaces for fog harvesting were created successfully using pol-jet 3D printing, hydrophobic coating, and hydrophilic polymeric composite.

- The water collection rate of the hybrid surfaces was compared to that of the hydrophilic and superhydrophobic samples. The dimension of the diameter and pitches of the hydrophilic regions in the hybrid surface significantly influence the WCR.

- The diameter of the hydrophilic region and the pitches varied to obtain the best WCR. The sample with $582 \pm 51$ um diameter and $1600 \pm 75$ pitch achieved $57 \%$ more water than the untreated hydrophilic surface.

- The novel method to create hybrid surfaces is scalable. It can be modifying to any curvature by detaching them from the mold after 30 min and attach them to any other surface.

- $\quad$ Further studies are needed to fully capitulate the influential factors on the fog harvesting mechanism and the relation among them

- The printing accuracy slightly affected the desired dimensions; other options for the manufacturing of the sheet might lead to better results

\section{ACKNOWLEDGEMENT}

This work was completed with funding from the US Department of Agriculture (Grant \# 2016-38422-25540). The authors would like to thank the USDA and Texas State University for providing funding and access to both infrastructure and laboratories. The sponsors are not responsible for the content and accuracy of this article. The authors declare that there is no conflict of interest regarding the publication of this paper.

\section{REFERENCES}

1. The Water in You: Water and the Human Body. (2021). Retrieved 17 March 2021, from https://www.usgs.gov/special-topic/water-science-school/science/water-you-water-and-human-body?qtscience_center_objects $=0 \#$ qt-science_center_objects

2. Human right to water and sanitation | International Decade for Action 'Water for Life' 2005-2015. (2021). Retrieved 17 March 2021, from

https://www.un.org/waterforlifedecade/human_right_to_water.shtml\#: :text=According\%20to\%20the\%20 World\%20Health,and\%20few\%2Ohealth\%20concerns\%20arise.

3. Human right to water and sanitation | International Decade for Action 'Water for Life' 2005-2015. (2021). Retrieved 17 March 2021, from https://www.un.org/waterforlifedecade/human_right_to_water.shtml\#: :text=According\%20to\%20the\%20 World\%20Health,and\%2Ofew\%20health\%20concerns\%20arise.

4. FAO. 2020. The State of Food and Agriculture 2020. Overcoming water challenges in agriculture. Rome.

5. Urbanization | UN-Water. (2021). Retrieved 18 March 2021, from https://www.unwater.org/waterfacts/urbanization/

6. Bhaduri, A., Bogárdi, J., Leentvaar, J., \& Marx, S. (2014). The global water system in the Anthropocene: challenges for science and governance. Springer. 
7. WWAP (United Nations World Water Assessment Programme)/UN-Water. 2018. The United Nations World Water Development Report 2018: Nature-Based Solutions for Water. Paris, UNESCO.

8. Howard Perlman, U. (2017). How much water is there on Earth. USCS Water Science School. Water.usgs.gov. Retrieved 25 March 2021, from https://water.usgs.gov/edu/earthhowmuch.html

9. Chen, Z., \& Zhang, Z. (2020). Recent progress in beetle-inspired superhydrophilic-superhydrophobic micropatterned water-collection materials. Water Science And Technology. doi: 10.2166/wst.2020.238.

10. Rajaram, M., Heng, X., Oza, M., \& Luo, C. (2016). Enhancement of fog-collection efficiency of a Raschel mesh using surface coatings and local geometric changes. Colloids And Surfaces A: Physicochemical And Engineering Aspects, 508, 218-229. doi: 10.1016/j.colsurfa.2016.08.034

11. Lee, A., Moon, M., Lim, H., Kim, W., \& Kim, H. (2012). Water harvest via dewing. Langmuir, 28(27), $10183-$ 10191. doi: 10.1021/la3013987.

12. Sharma, V., Sharma, M., Kumar, S., \& Krishnan, V. (2016). Investigations on the fog harvesting mechanism of Bermuda grass ( Cynodon dactylon ). Flora, 224, 59-65. doi: 10.1016/j.flora.2016.07.006.

13. Zhang, S., Huang, J., Chen, Z., \& Lai, Y. (2016). Bioinspired Special Wettability Surfaces: From Fundamental Research to Water Harvesting Applications. Small, 13(3), 1602992. doi: 10.1002/smll.201602992.

14. Parker, A., \& Lawrence, C. (2001). Water capture by a desert beetle. Nature, 414(6859), 33-34. doi: $10.1038 / 35102108$

15. Nørgaard, T., \& Dacke, M. (2010). Fog-basking behaviour and water collection efficiency in Namib Desert Darkling beetles. Frontiers In Zoology, 7(1), 23. doi: 10.1186/1742-9994-7-23.

16. Mondal, B., Mac Giolla Eain, M., Xu, Q., Egan, V., Punch, J., \& Lyons, A. (2015). Design and Fabrication of a Hybrid Superhydrophobic-Hydrophilic Surface That Exhibits Stable Dropwise Condensation. ACS Applied Materials \& Interfaces, 7(42), 23575-23588. doi: 10.1021/acsami.5b06759.

17. Hou, Y., Yu, M., Chen, X., Wang, Z., \& Yao, S. (2014). Recurrent Filmwise and Dropwise Condensation on a Beetle Mimetic Surface. ACS Nano, 9(1), 71-81. doi: 10.1021/nn505716b.

18. Garrod, R., Harris, L., Schofield, W., McGettrick, J., Ward, L., Teare, D., \& Badyal, J. (2007). Mimicking a Stenocara Beetle's Back for Microcondensation Using Plasmachemical Patterned Superhydrophobic-Superhydrophilic Surfaces. Langmuir, 23(2), 689-693. doi: 10.1021/la0610856.

19. Zhang, L., Wu, J., Hedhili, M., Yang, X., \& Wang, P. (2015). Inkjet printing for direct micropatterning of a superhydrophobic surface: toward biomimetic fog harvesting surfaces. Journal OfMaterials Chemistry $A, 3(6)$, 2844-2852. doi: 10.1039/c4ta05862c.

20. Gürsoy, M. (2020). All-dry patterning method to fabricate hydrophilic/hydrophobic surface for fog harvesting. Colloid And Polymer Science, 298(8), 969-976. doi: 10.1007/s00396-020-04656-x.

21. Moazzam, P., Tavassoli, H., Razmjou, A., Warkiani, M., \& Asadnia, M. (2018). Mist harvesting using bioinspired polydopamine coating and microfabrication technology. Desalination, 429, 111-118. doi: 10.1016/j.desal.2017.12.023.

22. Wang, Y., Zhang, L., Wu, J., Hedhili, M., \& Wang, P. (2015). A facile strategy for the fabrication of a bioinspired hydrophilic-superhydrophobic patterned surface for highly efficient fog-harvesting. Journal Of Materials Chemistry A, 3(37), 18963-18969. doi: 10.1039/c5ta04930j.

23. Park, J., \& Kim, S. (2019). Three-Dimensionally Structured Flexible Fog Harvesting Surfaces Inspired by Namib Desert Beetles. Micromachines, 10(3), 201. doi: 10.3390/mi10030201.

24. Wong, I., Teo, G., Neto, C. and Thickett, S., 2015. Micropatterned Surfaces for Atmospheric Water Condensation via Controlled Radical Polymerization and Thin Film Dewetting. ACS Applied Materials \& Interfaces, 7(38), pp.21562-21570.

25. Atomized, C., 2021. Buy Copper Atomized at Inoxia Ltd. [online] Inoxia.co.uk. Available at: <https://www.inoxia.co.uk/products/chemicals/elements/copper-atomized> [Accessed 19 April 2021].

26. Gorillatough.com. 2021. [online] Available at: <https://www.gorillatough.com/wp-content/uploads/GorillaEpoxy-Resin-3.pdf > [Accessed 19 April 2021].

27. Gorillatough.com. 2021. [online] Available at: <https://www.gorillatough.com/wp-content/uploads/GorillaEpoxy-Hardener-SDS-Update.pdf> [Accessed 19 April 2021].

28. Marmur, A., Della Volpe, C., Siboni, S., Amirfazli, A., \& Drelich, J. (2017). Contact angles and wettability: towards common and accurate terminology. Surface Innovations, 5(1), 3-8. doi: 10.1680/jsuin.17.00002.

29. Huhtamäki, T., Tian, X., Korhonen, J., \& Ras, R. (2018). Publisher Correction: Surface-wetting characterization using contact-angle measurements. Nature Protocols, 14(7), 2259-2259. doi: 10.1038/s41596-018-0047-0.

30. Drelich, J. (2013). Guidelines to measurements of reproducible contact angles using a sessile-drop technique. Surface Innovations, 1(4), 248-254. doi: 10.1680/si.13.00010.

31. Dorrer, C., \& Ruhe, J. (2008). Mimicking the Stenocara Beetle-Dewetting of Drops from a Patterned Superhydrophobic Surface. Langmuir, 24(12), 6154-6158. doi: 10.1021/la800226e.

32. Tang, X., \& Guo, Z. (2020). Biomimetic fog collection and its influencing factors. New Journal Of Chemistry, 44(47), 20495-20519. doi: 10.1039/d0nj04632a.

33. Lei, J., \& Guo, Z. (2020). A fog-collecting surface mimicking the Namib beetle: its water collection efficiency and influencing factors. Nanoscale, 12(13), 6921-6936. doi: 10.1039/c9nr10808d 
34.Zhu, H., Huang, Y., Lou, X., \& Xia, F. (2019). Beetle-inspired wettable materials: from fabrications to applications. Materials Today Nano, 6, 100034. doi: 10.1016/j.mtnano.2019.100034

35. Chaudhury, M., \& Whitesides, G. (1992). How to Make Water Run Uphill. Science, 256(5063), 1539-1541. doi: 10.1126/science.256.5063.1539 